\title{
DESKRIPSI SANITASI PONDOK PESANTREN MA'HADUT THOLABAH KABUPATEN TEGAL TAHUN 2016
}

\author{
Jaman Ali Murtako ${ }^{1)}$, Khomsatun ${ }^{2)}$ \\ Jurusan Kesehatan Lingkungan, Politeknik Kesehatan Kemenkes Semarang, \\ Jl. Raya Baturaden KM 12 Purwokerto, Indonesia
}

\begin{abstract}
Abstrak
Suatu pondok pesantren harus memenuhi persyaratan sanitasi supaya setiap santri dan pengunjung yang ada di pondok pesantren bebas dan aman dari ancaman gangguan kesehatan. Tujuan dari penelitian ini untuk mengetahui kondisi sanitasi pondok pesantren Ma'hadut Tholabah Kabupaten Tegal yang meliputi keadaan lingkungan dan bangunan, kepadatan santri dalam satu kamar, penyediaan air bersih, pengelolaan makanan dan minuman, pengelolaan sampah, pembuangan air limbah, pengendalian vektor dan binatang pengganggu. Metode yang digunakan dalam penelitian ini yaitu deskriptif, pengumpulan data dilakukan dengan cara wawancara, observasi, dan pengukuran, analisis data secara deskriptif digunakan untuk menggambarkan kondisi asrama yang berasal dari hasil penelitian. Hasil penelitian yang diperoleh dari kondisi sanitasi pondok pesantren yaitu lingkungan pondok pesantren aman dan nyaman, kondisi bangunan sangat baik dan memenuhi persyaratan; kepadatan santri masih belum memenuhi persyaratan; penyediaan air bersih baik; pengelolaan makan dan minuman baik; pengelolaan sampah sangat baik; pembuangan air limbah kurang baik; pengendalian vektor dan binatang pengganggu cukup. Simpulan dari penelitian yang telah dilakukan adalah kondisi sanitasi pondok pesantren baik dan masuk dalam kategori memenuhi syarat, penilaian diambil dari hasil checklis.
\end{abstract}

Kata kunci : Sanitasi; Pondok Pesantren

\begin{abstract}
Muslim boarding school should be complying a sanitary requirement so that each student and visitors in the muslim boarding school are free and safe from the threat of health problems. The purpose of this study to determine the sanitary conditions at The muslim boarding school's which include for the state of the environment and the building, the density of students in the room, the provision of clean water, food and beverage management, waste management, waste water disposal, vector control and vermin. The method used in this research is descriptive, data collection was done by interview, observation, and measurement, data descriptive analysis is used to describe the condition of the muslim boarding school are derived from the research. The results obtained from the sanitary condition hostel dorms are safe and comfortable environment, excellent condition of the building and complied the requirements; the density of the students still do not complied the standard; provision of clean water is good enough; management of food and drink is good enough; waste management has been very good; wastewater disposal is good enough; vector control and nuisance animals quite well. The conclusions of the research that has been done is the sanitary conditions muslim boarding school has been quite good and included in the category qualify, ranting is checklis.
\end{abstract}

Keywords : Sanitation; Muslim Boarding School

\section{PENDAhUluan}

Upaya kesehatan adalah setiap kegiatan atau serangkaian kegiatan yang dilakukan secara terpadu, terintegrasi dan berkesinambungan untuk memelihara dan meningkatkan derajat kesehatan masyarakat dalam bentuk pencegahan penyakit, peningkatan kesehatan, pengobatan penyakit, dan pemulihan kesehatan oleh pemerintah dan masyarakat. Sarana dan bangunan umum merupakan tempat dan atau alat yang dipergunakan oleh masyarakat umum untuk melakukan kegiatannya, oleh karena itu perlu dikelola demi kelangsungan kehidupan dan penghidupannya untuk mencapai keadaan sejahtera dari badan, jiwa dan sosial, yang memungkinkan penggunanya hidup dan bekerja

1) Email : jamianalimurtako@gmail.com

2) Email : daplunrokhim@gmail.com dengan produktif secara sosial ekonomis. Banyak ditemukan di kalangan masyarakat khususnya yang tinggal di pondok pesantren terjangkit suatu penyakit. Kepadatan hunian ruangan ikut berperan dalam penularan penyakit berbasis lingkungan seperti Scabies, yaitu berpindahnya reservoir ke barang sekitarnya hingga menimbulkan rantai penyakit yang kemungkinan dapat menjangkiti semua anggota Asrama. Pondok Pesantren Ma'hadut Tholabah memiliki 42 kamar dengan tiap kamar ditempati oleh kurang lebih 12 santri dengan jumlah 586 santri. Kondisi sanitasi di lingkungan pondok pesantren yang tidak mendukung dapat mempengaruhi kesehatan, sampai saat ini masalah keadaan lingkungan pada pondok pesantren tersebut 
masih ada terutama dalam hal sanitasi diantaranya penyakit yang berbasis lingkungan seperti Diare dan Scabies yang sering terjadi setiap tahunnya.

Tujuan umum dari penelitian ini untuk mengetahui keadaan sanitasi Pondok Pesantren Ma'hadut Tholabah Kabupaten Tegal Tahun 2016, sedangkan tujuan khusus ditujukan pada Pondok Pesantren Ma'hadut Tholabah Kabupaten Tegal Tahun 2016 diantaranya mengetahui keadaan lingkungan dan bangunan, mengetahui kepadatan santri yang menempati dalam satu kamar, mengetahui penyediaan air bersih, mengetahui pengelolaan makanan dan minuman, mengetahui pengelolaan sampah, mengetahui saluran pembuangan air limbah, Mengetahui pengendalian vektor dan binatang pengganggu.

\section{METODE PENELITIAN}

Metode jenis penelitian ini adalah deskriptif yaitu penelitian yang bertujuan untuk mendeskripsikan satu atau lebih variabel penelitian secara mendalam, tanpa untuk mengetahui perbedaan atau hubungan nilai/data antar variabel.

Subyek penelitian ini adalah sanitasi Pondok Pesantren Ma'hadut Tholabah Kabupaten Tegal, dengan variabel yang akan diteliti meliputi keadaan sanitasi lingkungan dan bangunan, kepadatan santri yang menempati satu kamar, penyediaan air bersih, pengelolaan makanan dan minuman, pengelolaan sampah, saluran pembuangan air limbah, pengendalian vektor dan binatang pengganggu.

Tabel 1 Ruang Lingkup

\begin{tabular}{|l|l|}
\hline \multicolumn{2}{|c|}{ Waktu } \\
\hline Tahap Persiapan & September -Februari 2016 \\
\hline Tahap Pelaksanaan & Maret -April 2016 \\
\hline Tahap Penyelesaian & Mei -Juni 2016 \\
\hline
\end{tabular}

Sumber data dibagi menjadi dua macam yaitu data primer dan data sekunder, pengumpulan data berasal dari data umum dan data khusus diantaranya data tentang keadaan geografis, keadaan wilayah, gambaran umum asrama, jumlah santri dan sarana sanitasi yang ada; sedangkan data khusus antara lain keadaan sanitasi lingkungan dan bangunan, kepadatan santri yang menempati satu kamar, penyediaan air bersih, pengelolaan makanan dan minuman, pengelolaan sampah, saluran pembuangan air limbah, pengendalian vektor dan binatang pengganggu. Cara pengumpulan data yaitu dengan teknik pengumpulan data, langkah-langkah yang dilakukan dalam pengumpulan data penelitian dapat dilakukan dengan cara observasi dan pengukuran. Instrumen pengumpulan data diantaranya pengukuran suhu menggunakan thermometer, pengukuran kelembaban menggunakan hygrometer, pengukuran intensitas cahaya menggunakan luxmeter, observasi menggunakan checklist. Pengolahan data dilakukan dengan cara editing, coding dan tabulating.

Etika dalam melakukan penelitian,peneliti akan mengajukan permohonan ijin, kepada instansi setempat untuk mendapatkan persetujuan, kemudian cheklist diberikan ke subjek yang diteliti dengan menentukan pada masalah yang menekankan prinsip-prinsip etika yang meliputi Informed concent atau lembar persetujuan responden, Anonymity atau tanpa nama, Confidentiality atau kerahasiaan.

\section{HASIL DAN PEMBAHASAN}

Hasil pengamatan yang telah dilakukan secara langsung diperoleh data yaitu lokasi pondok pesantren Ma'hadut Tholabah tidak berada pada daerah bekas pembuangan akhir sampah, tidak terletak pada daerah rawan bencana alam seperti bantaran sungai, terhindar dari longsor dan banjir, Pondok pesantren juga tidak terletak pada daerah rawan kecelakaan dan daerah kebakaran, lokasi pondok pesantren ini sudah memenuhi syarat sesuai dengan Keputusan Menteri Kesehatan Republik Indonesia No. 829 / MENKES / SK / VII / 1999.

Lingkungan pondok pesantren Ma'hadut Tholabah dilengkapi dengan pembatas tembok dan pagar yang terbuat dari besi, berdasarkan persyaratan kesehatan lingkungan menurut Dirjen PPM dan PL tahun 2000 lingkungan di pondok pesantren sudah memenuhi syarat; dinding pada pondok pesantren sudah sesuai dengan persyaratan kesehatan lingkungan menurut Dirjen PPM dan PL tahun 2000 yaitu dinding selalu bersih, terbuat dari bahan yang kedap air dan mudah dibersihkan; berdasarkan persyaratan Kesehatan Lingkungan menurut Dirjen PPM dan PL tahun 2000 kondisi lantai di pondok pesantren belum sesuai sebaiknya lantai dalam kondisi bersih, terbuat dari bahan yang kedap air, tidak licin dan mudah dibersihkan, tetapi lantai masih perlu adanya perbaikan untuk lantai yang kondisinya cekung; atap dan langit-langit menggunakan genteng yang sudah sesuai dengan persyaratan kesehatan lingkungan menurut Dirjen PPM dan PL tahun 2000 yaitu kuat dan tidak bocor; tinggi langit-langit dari lantai adalah $3 \mathrm{~m}$, bahan yang kuat, berwarna terang, keadaan bersih dan mudah dibersihkan dan sudah memenuhi persyaratan menurut keputusan menteri kesehatan republik indonesia No. 829/MENKES/SK/VII/1999 yaitu langit-langit terbuat dari bahan yang kuat, berwarna terang dan mudah dibersihkan, dan tinggi langitlangit antara 2,5 meter dari lantai; pintu dan jendela yang ada di barak sudah sesuai dengan persyaratan kesehatan lingkungan menurut Dirjen PPM dan PL tahun 2000 yaitu secara keseluruhan baik, dapat dibuka, ditutup dan dikunci dengan baik, pintu dan jendela barak dapat mencegah binatang tikus; ventilasi terletak berseberangan sehingga mempermudah sirkulasi udara ( Cross Ventilation ) sudah memenuhi syarat menurut Keputusan Menteri Kesehatan Republik Indonesia No. 829/MENKES/SK/VII/1999; rata-rata kondisi kelembaban ruangan pagi $77,71 \%$ dan malam $85,07 \%$ sedangkan suhu ruangan pagi adalah $31,19^{\circ} \mathrm{C}$ dan malam $28,73^{\circ} \mathrm{C}$, menurut Direktur 
Jendral PPM dan PL kelembaban ruangan adalah 65$95 \%$ dan suhu udara standar adalah $15^{\circ} \mathrm{C}-30^{\circ} \mathrm{C}$, sedangkan menurut Keputusan Menteri Kesehatan RI No. 829/MENKES/SK/VII/1999 intensitas cahaya minimal adalah 60 lux dan atau tidak menyilaukan, berdasarkan hal tersebut pencahayaan ruangan sudah memenuhi syarat kesehatan.

Tabel 1 Hasil Pemeriksaan dan Pengukuran Sanitasi Pondok Pesantren

\begin{tabular}{|c|c|c|}
\hline No & $\begin{array}{c}\text { Komponen } \\
\text { Pemeriksaan }\end{array}$ & Kategori \\
\hline 1 & $\begin{array}{l}\text { Sanitasi lingkungan, } \\
\text { ruang, dan bangunan }\end{array}$ & Baik \\
\hline 2 & $\begin{array}{lll}\begin{array}{l}\text { Sanitasi } \\
\text { ruang }\end{array} & \text { kamar atau } \\
\end{array}$ & Sangat Baik \\
\hline 3 & Penyediaan air bersih & Sangat Baik \\
\hline 4 & \begin{tabular}{|lll}
$\begin{array}{l}\text { Jamban dan } \\
\text { mandi }\end{array}$ & kamar \\
\end{tabular} & $\begin{array}{ll}\text { Belum } \\
\text { syarat }\end{array}$ \\
\hline 5 & Pengelolaan sampah & Sangat Baik \\
\hline 6 & Saluran pembuangan air & Kurang Baik \\
\hline 7. & $\begin{array}{ll}\text { Pengelolaan makanan } \\
\text { dan minuman }\end{array}$ & Baik \\
\hline 8. & Pengendalian vektor & Cukup \\
\hline
\end{tabular}

Perbandingan jumlah tempat tidur dengan luas ruangan belum memadai yaitu $1,54 \mathrm{~m}^{2}$ per orang. sedangkan menurut Dirjen PPM dan PL tahun 2000 luas lantai untuk setiap satu tempat tidur paling tidak adalah $4,5 \mathrm{~m}^{2}$.

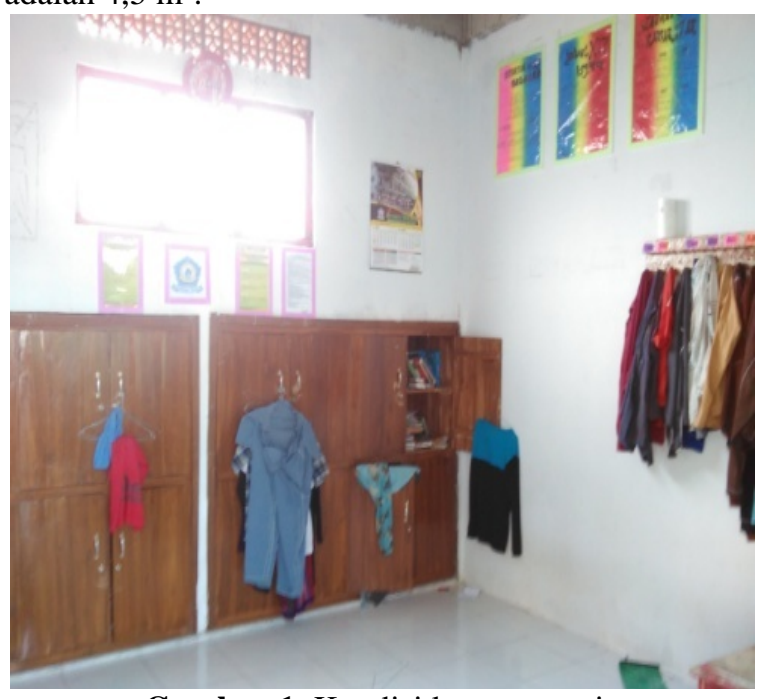

Gambar 1. Kondisi kamar santri

Sumber air bersih di pondok pesantren Ma'hadut Tholabah berasal dari sumur gali, secara kualitas fisik air bersih sudah sesuai dengan Permenkes No 416/MENKES/Per/IX1990 yaitu tidak berbau, tidak berwarna dan tidak berasa.

Persyaratan sanitasi makanan mengacu pada 6 prinsip hygiene antara lain pengadaan bahan makanan, penyimpanan bahan makanan, pengolahan makanan, pengangkutan makanan, penyimpanan makanan jadi, dan penyajian makanan;

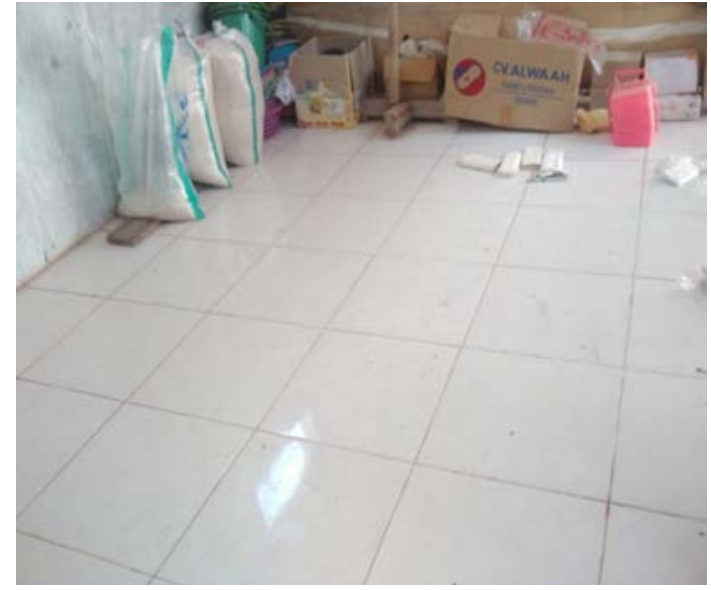

Gambar 2. Tempat persiapan makanan

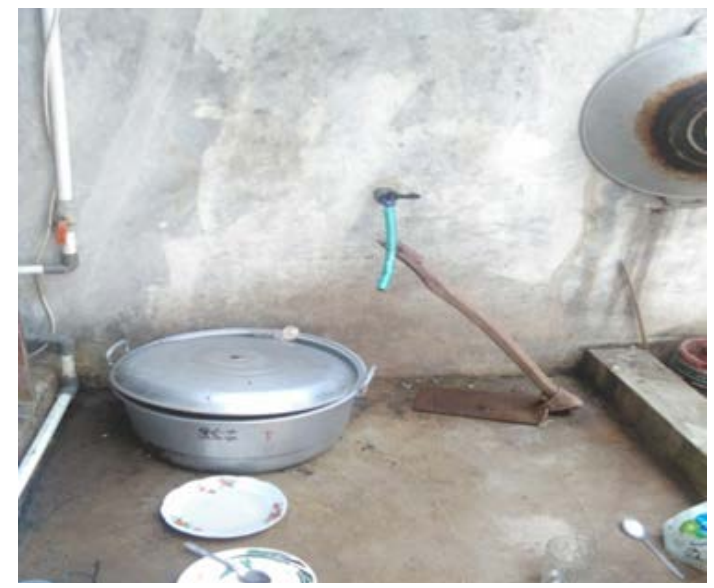

Gambar 3. Tempat mencuci peralatan makanan

Setiap kamar diberi tempat sampah dari bahan yang kuat, ringan, tahan karat dan kedap air sebanyak satu buah yang diletakkan di dekat pintu masuk dan sehingga mudah dijangkau oleh santri. Tempat sampah tersebut permukaan bagian dalam halus dan rata, selain itu tidak mempunyai tutup. Tempat sampah tiap hari dikosongkan oleh santri piket dan dibuang di Tempat Pembuangan Sementara. Frekuensi pengosongan TPS adalah tiga dalam satu minggu. Hal tersebut menunjukkan bahwa Pengolahan sampah di pondok pesantren sudah baik, sampah yang berasal dari kamar, dapur dan kantor dikumpulkan pada tempat sampah sementara yang sudah ada, kemudian tempat sampah tersebut dikosongkan 1x24 jam pada pagi hari dan sore hari, yang dilakukan oleh santri.

Pembuangan tinja pada pondok pesantren Ma'hadut Tholabah sudah memenuhi dengan persyaratan kesehatan lingkungan menurut Dirjen PPM dan PL tahun 2000 yaitu saluran pembuangan kotoran dialirka ke septik tank dan letak septik tank yang tidak berhubungan langsung dengan sumber air bersih, sehingga tidak mencemari air bersih yang ada dan menghindari bau dari pembuangan kotoran; pembuangan air limbah dari dapur pada pondok pesantren menggunakan saluran yang terbuka, kedap air dan dialirkan kesungai, hal tersebut belum sesuai dengan persyaratan kesehatan lingkungan menurut 
Dirjen PPM dan PL tahun 2000 yaitu saluran pembuangan air limbah tertutup, kedap air, aliran lancar dan dialirkan ke saluran pengolahan, sebaiknya perlu dibuatkan 1 bak pengendap untuk menyaring air limbah sebelum dibuang ke sungai agar tidak mencemari sungai; satu kamar yang ditempati oleh sedikitnya 34 di fasilitasi jamban sebanyak 1 jamban, hal tersebut belum sesuai dengan persyaratan kesehatan lingkungan menurut Dirjen PPM dan PL tahun 2000 yaitu jumlah penghuni 50-72 orang tersedia 8 buah jamban/kamar mandi, dengan jumlah penghuni kamar 15 siswa mempunyai jamban/kamar mandi sejumlah 1 buah masih belum mencukupi, sebaiknya perlu adanya penambahan jamban/kamar mandi.

Pengendalian vektor di pondok pesantren Ma'hadut Tholabah yang telah dilakukan adalah dengan melakukan kerja bakti setiap seminggu sekali, pengendalian vektor tersebut telah sesuai dengan Peraturan Menteri Kesehatan Republik Indonesia No. 374 / MENKES / PER / III / 2010 yaitu pengendalian vektor terpadu dengan metode pengendalian fisik dan mekanis sebagai upaya untuk mencegah, mengurangi, menghilangkan habitat perkembangbiakan dan populasi vektor.

\section{SIMPULAN DAN SARAN}

\section{Simpulan}

Lokasi di Pondok Pesantren Ma'hadut Tholabah sudah memenuhi syarat, perbandingan jumlah tempat tidur dengan luas ruangan belum memadai, sumber air bersih di pondok pesantren Ma'hadut Tholabah berasal dari sumur gali, pengelolaan makanan dan minuman di pondok pesantren telah memenuhi syarat dengan persentase $75 \%$, pengelolaan sampah di pondok pesantren tiap hari dikosongkan oleh santri piket dan dibuang di Tempat Pembuangan Sementara, pembuangan air limbah dari dapur di pondok pesantren belum sesuai dengan persyaratan kesehatan lingkungan menurut Dirjen PPM dan PL tahun 2000, pengendalian vektor pada pondok pesantren dalam kategori cukup dengan persentase $<34 \%$.

\section{Saran}

Berdasarkan pemeriksaan yang telah dilakukan, penelitian memberi saran kepada pihak pondok pesantren mengenai upaya sanitasi adalah sebagai berikut:

1. Pemberian tempat sampah yang terdapat tutup dan tempat sampah dibedakan antara sampah organik dan non organik,

2. Penambahan tempat sampah pada setiap kamar santri,

3. Pemberian resapan untuk saluran pembuangan air limbah dilengkapi dengan tutup sehingga tidak menimbulkan bau,

4. Dapur dilengkapi dengan alat pengeluaran udara panas,
5. Penjamah makanan memakia alat pelindung diri (celemek, sarung tangan, masker, penutup kepala),

6. Dapur dilengkapi dengan westafel,

7. Sebaiknya di ruang makan diberi tambahan wastafel, agar dapat selalu menjaga kebersihan tangan,

8. Kamar atau ruang sebaiknya dilengkapi dengan kawat kasa di bagian ventilasi agar mencegah masuknya nyamuk,

9. Sarana penyimpanan air ( tandon air ) sebaiknya diberi tutup agar terbebas dari jentik,

10. Penambahan jamban dan kamar mandi,

11. Melakukan pengaturan pemerataan jumlah penghuni kamar disesuaikan dengan luas kamar atau penambahn kamar, sebaiknya luas kamar $16 \mathrm{~m}^{2}$ jumlah penghuni 4 santri, $20 \mathrm{~m}^{2}$ jumlah penghuni 5 santri, $36 \mathrm{~m}^{2}$ jumlah penghuni 8 santri dan $42 \mathrm{~m}^{2}$ jumlah penghuni 8 santri.

\section{DAFTAR PUSTAKA}

Azrul,Azwar, 1986, Pengantar Ilmu Kesehatan Lingkungan, Jakarta: Mutiara Sumber Widya

Departemen Kesehatan RI, 1993, Peraturan Menteri Kesehatan RI dan Keputusan Direktur Jenderal PPM \& PLTentang Persyaratan Kesehatan Rumah Sakit. Jakarta: Kementerian Kesehatan.

Departemen Kesehatan RI, 1995, Peraturan Menteri Kesehatan RI dan Keputusan Direktur Jenderal PPM \& PL Tentang Persyaratan Kesehatan Hotel. Jakarta: Departermen Kesehatan.

Hilal Ahmar, 2013, di akses pada hari Senin, 23 Januari Pukul 23:23 WIB at ttp://majalahhilalahmarsolo.blogspot.co.id/2013/09/seha t-lingkungan-perlukah-pondok.htm

http://www.e-jurnal.com/2013/11/hubungan-tingkatpengetahuan-ibu.htmldi Akses pada hari Rabu, 27 Januari 2016 Pukul 16:08 WIB.

Iskandar Engku, 2014, Sejarah Pendidikan Islami, Bandung: PT Remaja Rosdakarya .

Keputusan Menteri Kesehatan, 1999, Keputusan Menteri Kesehatan Republik Indonesia Nomor 829/MENKES/SK/VII/1999 Tentang Persyaratan Kesehatan Perumahan dan Pemukiman, Jakarta: Kementerian Kesehatan.

Keputusan Menteri Kesehatan, 2003, Keputusan Menteri Kesehatan Republik Indonesia Nomor : 288/Menkes/SK/III/2003 Tentang 
Persyaratan sanitasi bangunan, Jakarta: Kementerian Kesehatan.

Notoatmodjo, Soekidjo, 2007, Kesehatan Masyarakat, Ilmu dan Seni, Jakarta : Rineka Cipta.

Notoatmodjo, Soekidjo, 2010, Metodologi Penelitian Kesehatan, Jakarta: Rineka Cipta.

Sarudji, Didik, 2010,Kesehatan Lingkungan, Bandung: CV. Karya Putra Darwati.
Suparlan, 1988, Pedoman Pengawasan Sanitasi Tempat-Tempat Umum, Surabaya: Merdeka Print

Tri Cahyono. 2014. Pedoman Penulisan Proposal Penelitian dan Karya Tulis Ilmiah/Skripsi ( Edisi Revisi Ketiga ). Purwokerto : Jurusan Kesehatan Lingkungan Poltekkes Kemenkes Semarang. 